\title{
A teoria habermasiana de inclusão do outro e a internação compulsória ${ }^{1}$
}

\section{The habermasian theory of inclusion of the other and compulsory internment}

DOI: $10.46814 /$ lajdv3n5-016

Recebimento dos originais: 01/05/2021

Aceitação para publicação: 31/06/2021

\section{Carolina Nunes de Freitas}

Mestre em Direitos e Garantias Fundamentais pela Faculdade de Direito de Vitória (FDV). Pósgraduada em Direito Constitucional PUC-MG. Graduada em Direito e em Comunicação Social com habilitação em Jornalismo (FAESA). Membra do Biogepe - Grupo de Pesquisa e Extensão em Políticas Públicas, Direito à Saúde e Bioética. Bolsista da Fapes. Professora de Direito das Sucessões,

Direito Internacional e Empresarial da Faculdade Novo Milênio em Vila Velha/ES. Advogada.

E-mail: carolina_nf@yahoo.com.br

\section{RESUMO}

Artigo científico desenvolvido a partir das discussões durante as aulas de mestrado, após verificada a necessidade de compreender a internação compulsória, sob a perspectiva habermasiana da inclusão do outro. O estudo apresentou os principais elementos caracterizadores da inclusão do outro e a previsão legal de internação compulsória de usuários abusivos de drogas que, embora partam de pontos distintos, podem interagir e auxiliar ao Direito.

Palavras-chaves: Jürgen Habermas. Inclusão do Outro. Internação Compulsória

\section{ABSTRACT}

Scientific paper developed from discussions during master's classes, after verifying the need to understand compulsory hospitalization, from the Habermasian perspective of inclusion of the other. The study presented the main elements that characterize the inclusion of the other and the legal provision of compulsory hospitalization of drug abusers who, although starting from different points, can interact and assist the Law

Keywords: Jürgen Habermas. Inclusion of the other. compulsory hospitalization

\section{INTRODUÇÃO}

\begin{abstract}
Mas de todas essas naves romanescas ou satíricas, a Narrenschiff é a única que teve existência real, pois eles existiram, esses barcos que levavam sua carga insana de uma cidade para outra. Os loucos tinham então uma existência facilmente errante. As cidades escorraçam-nos de seus muros; deixava-se que corressem pelos campos distantes, quando não eram confiados a grupos de mercadores e peregrinos. (FOCAULT, 2005,p. 9).
\end{abstract}

\footnotetext{
${ }^{1}$ Artigo Científico apresentado na disciplina de Direitos Fundamentais do Curso de Pós-Graduação Stricto Sensu em Direitos e Garantias Fundamentais da Faculdade de Direito de Vitória,sob a orientação do professor e Doutor Alexandre Coura.
} 
Desde que Foucault redigiu sua história da loucura tornou-se quase impensável para nós não ver em política públicas que sugiram o afastamento de um determinado grupo de seu convívio social como um retorno ás épocas longínquas nas quais se fazia uso da Narrenschiff.

Desde aquela época a solução de quaisquer problemas sócias consistia em unicamente extirpar do meio da sociedade os grupos julgados pela maioria como problemáticos. Não se lhes prestava ouvidos ou se buscava o fundamento ou bases sobre os quais se erigiu determinado problema. De um só golpe tudo se transformava em tranquilidade com a partida de uma "nau dos loucos" para longe daqueles considerados normais.

Ainda hoje esse tendência se faz sentir em nosso meio quando as políticas pública que visam garantir a saúde, educação e bem-estar social da população são substituídas sutilmente por políticas de exclusão social e tentativas de minorar problemas para os quais por anos a fio têm sido colocados em planos inferiores de atenção e para os quais o poder público deveria ter dado atenção.

A política de internação compulsória nos sugere que algo deste tipo está se repetindo. Ela parece ser uma "política emergencial" feita de última hora para sanar um problema negligenciado em sua seriedade.

Para a análise dessa política se faz em primeiro lugar uma exposição do pensamento habermasiano a respeito da inclusão do outro dentro de seu referencial teórico e da estrutura de seu pensamento. Quer-se, com isso, fornecer um arcabouço teórico sistemático pertinente a temática tratada neste trabalho.

Em seguida, tem-se uma breve exposição da política de internação compulsória. Tal exposição não se delonga na citação de leis, mas se centra naquilo que é fundamental e pertinente para a análise visando evitar prolixidades desnecessárias. Trata-se de uma abordagem pontual da visão jurídicohistórica assomada a seus contextos.

Segue-se assim uma comparação entre a política de internação compulsória e a teoria habermasiana de inclusão do outro. Ali se elencam os principais elementos conflitivos entre ambas e que devem ser postos ao lume da razão para que a mesma averigue a procedência dos argumentos.

Por fim, oferece-se uma apreciação, à guisa de conclusão, sobre o que se pode afirmar de tudo o que foi pesquisado neste trabalho. Não se tencionando, obviamente, esgotar o assunto, mas marcando a postura que esta pesquisa mostrou mais pertinente e embasada. 


\section{A IDEIA HABERMASIANA DE INCLUSÃO DO OUTRO \\ 2 A IDEIA HABERMASIANA DE INCLUSÃO DO OUTRO}

Jürgen Habermas, filósofo e sociólogo alemão nascido em Düsseldorf no ano de 1929, pode ser considerado um dos membros mais destacados da segunda geração de filósofos da Frankfurter Schule (Escola de Frankfurt) e a última grande figura da tradição filosófica que se inspira em Karl Marx e Georg Wilhelm Friedrich Hegel para realizar uma interpretação sócio-histórica do mundo atual. O que nos permite alocar de maneira esquemática, desde o ponto da História da Filosofia (cf. UREÑA, 1978, p. 15), seu pensamento da seguinte maneira:

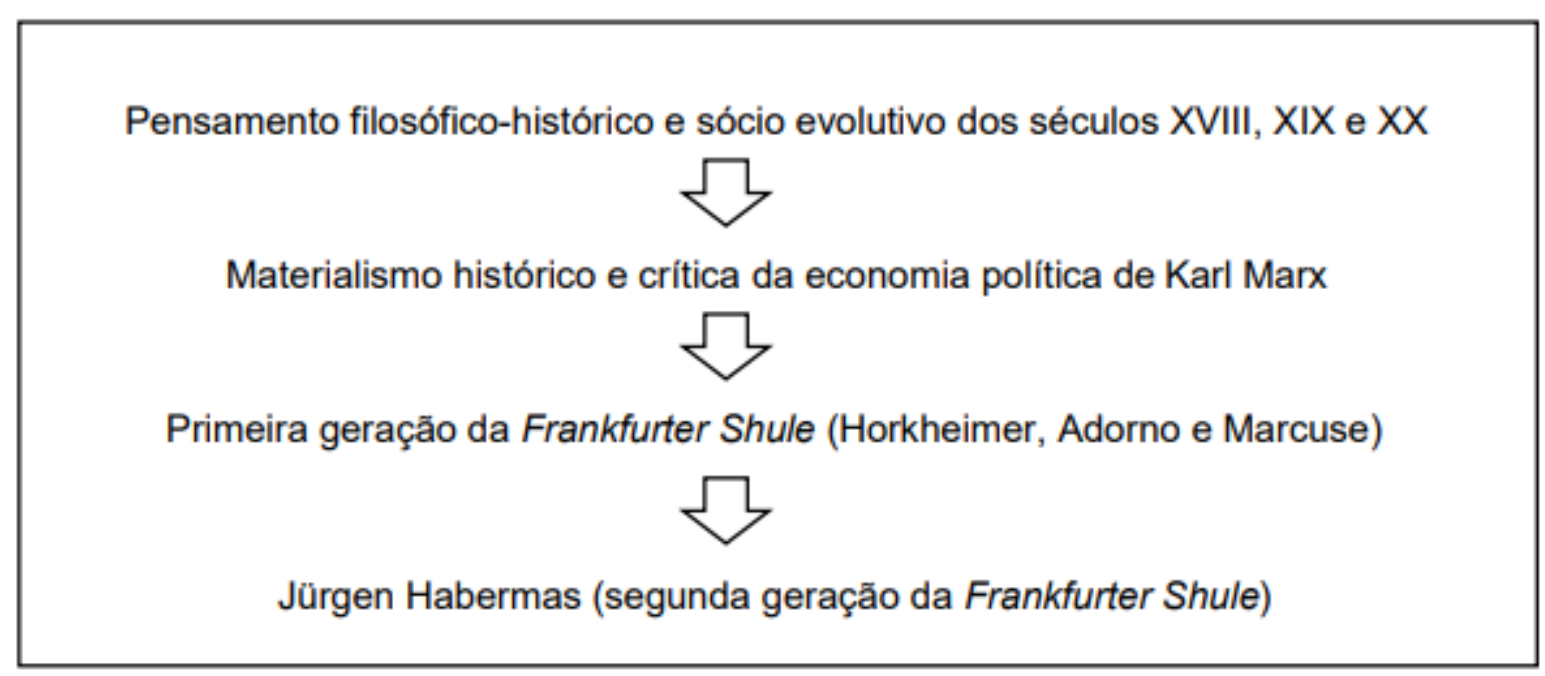

Após uma primeira etapa na qual Habermas seguiu diretamente os pleiteamentos da teoria crítica (conforme delineada por Horkheimer e Adorno - dos quais ele fora discípulo), renova esta mesma teoria, mantendo a perspectiva de oposição ao cientificismo positivista e de esforço de transformação da sociedade mediante a reflexão crítica, apoiando-se mais que na tradição idealista na nova filosofia da linguajem (cf. HABERMAS, 1999 e 1992, respectivamente). Formula, assim, sua doutrina da "situação ideal de diálogo" como núcleo de sua teoria (HABERMAS, 1989).

Para Habermas toda ciência supõe uma relação com o interesse, posto que os interesses formam parte constitutiva do conhecimento e da razão (HABERMAS, 1983). Distinguem-se, portanto, três formas de interesses e, por isso, três classes de ciências: 
As três formas de interesses e três classes de ciências conforme Habermas

[1]

Ciências empíricas

Ciências da natureza seguem 0 interesse

técnico da razão regulado pela objetividade.
[2]

\section{Ciências histórico-hermenêuticas}

Ciências do espirito - que correspondem com o interesse prático que se regula pela intersubjetividade.
[3]

\section{Ciências emancipativas}

Se vinculam ao interesse emancipador, à reflexão crítica.

É desse novo terceiro tipo, Ciências emancipativas, que segundo Habermas se deve ocupar num tratamento sério a teoria crítica. A emancipação progressiva do ser humano é levada a cabo, já segundo a teoria crítica da primeira Escola de Frankfurt, através da crítica às ideologias - crítica à ciência e à técnica - e do recurso à psicanálise (MATOS, 1993).

Assim a teoria deixa de ser mera teoria e coincide com a práxis, pois em ambos os casos coincidem o conhecimento (teórico) com o interesse (prático): a crítica à sociedade não consiste num mero compreender, senão na emancipação das diversas formas injustas de dominação e, no labor psicanalítico, o simples compreender já é libertação (HABERMAS, 1987).

Não se deve nunca separar a racionalidade do interesse; a prova disso está na própria linguajem. Esta supõe essencialmente comunicação e o diálogo constitui a forma ideal de comunicação. Não há situação possível de diálogo se os sujeitos não se reconhecem mutuamente na plena igualdade de seres livres e responsáveis. A igualdade humana, à qual tende toda a tradição do idealismo hegeliano e do materialismo histórico, aparece exigida como situação radical e originária do diálogo: no diálogo dos seres livres e autônomos surge a ideia.

Não obstante a tudo isso, a situação real, o diálogo real na sociedade, não manifesta tal situação ideal; porém a compreensão desta "situação ideal de diálogo" é o a priori do qual há de se partir e algo que todavia não existe, porém que se percebe como o único que possibilita a vida boa e que os sujeitos humanos plenamente livres sejam capazes de compreensão: de intersubjetividade. À ciência desta intersubjetividade Habermas denomina "pragmática universal” (HABERMAS, 1999, especialmente a seção intitulada “¿Qué significa pragmática universal?”).

Com o transcorrer do tempo Habermas integra a seu programa filosófico um texto de suma importância denominado Die Einbeziehung des Anderen (“A inclusão do outro”), cujo subtítulo dá a tônica da especificidade dessa inclusão à qual o trabalho faz referência: Studien zur politischen Theorie 
("Estudos de teoria política"). Nele Habermas quer dar continuidade a seu programa filosófico, conforme exposto até aqui, pensando as coordenadas mais propositivas e possíveis para o tempo atual e ressaltando como seu sistema filosófico pode dar imprescindíveis contribuições para a resolução das questões político-sociais.

Publicado em 1996 e composto de ensaios, o livro inicia com um ensaio que pode parecer destoar dos demais, mas que, na verdade, funciona como porta para os escritos que lhe sucederão: "Uma visão genealógica do teor cognitivo da moral" (HABERMAS, 2002, p. 11-60). É um ensaio referente às questões básicas da filosofia moral habermasiana que regulam toda a estrutura de seu pensamento e auxiliam o leitor na compreensão do marco teórico do restante dos textos.

Nos demais ensaios Habermas se empenha em fornecer um detalhado exame das pré-condições sociais, culturais e institucionais às quais está submetida a execução dos discursos práticos, bem como das barreiras com as quais estes se deparam. Isto porque o conteúdo temático se inscreve numa época em que Habermas havia infundido em seu pensamento social, cujo texto exponencial é Faktizität und Geltung ("Facticidade e Validez", cf. HABERMAS, 2005), a tensão existente entre os pleiteamentos normativistas e os sociológicos observáveis na filosofia política e jurídica atual.

É assim que, subsidiado pela teoria discursiva do direito e do Estado, desenvolve a temática da inclusão do outro levando em consideração os distintos âmbitos e problemas do mundo atual. Portanto, aplica em sua formulação teórica os princípios democráticos da política deliberativa: a progressiva integração dos mercados internacionais, a globalização dos meios de comunicação, a crescente diversidade cultural das sociedades contemporâneas e seus conflitos com a globalização, o esvaziamento da democracia, a tomada de consciência do caráter global dos direitos humanos, etc.

Todas estas perspectivas que Habermas leva em consideração na sua análise (por exemplo: o direito de manter a própria vida cultural e a obrigação de aceitar o marco político de convivência definido pelos princípios constitucionais e os direitos humanos), fazem com que sugira uma tentativa de impedir que a identidade coletiva se torne um mecanismo de exclusão do diferente. Sendo que tal exclusão se dá por meio de uma vontade consciente de homogeneidade social e que provoca a marginalização interna de grupos sociais inteiros.

Sua proposta contra a exclusão sistemática consiste na defesa de que a política própria da democracia deve ser dirigida na direção da "inclusão do outro". Uma inclusão que promova a independência da procedência cultural de cada qual e as vias de acesso à comunidade política que devem permanecer sempre abertas. E a condição para isso é que, no maior grau possível, as instituições públicas se dispam de conotações morais densas e passem a adotar integralmente os procedimentos do direito moderno. Pois, para Habermas, somente este tipo de reforma judiciária torna factível o estabelecimento de relações de respeito mútuo entre sujeitos distintos e até estranhos entre si. 
Diante de qualquer tentação de exclusão a teoria habermasiana advoga em prol de um "patriotismo constitucional" pelo qual os cidadãos se identifiquem com os princípios da própria constituição - identificação essa que implica para os indivíduos uma compreensão da constituição como uma conquista vincada dentro da história de seu pais e a concepção da liberdade da nação de maneira universalista.

A visão de Habermas no que diz respeito ao processo de inclusão do outro é, portanto, uma visão cosmopolita e aberta da comunidade política como uma nação de cidadãos. Tendo como pressuposto que já passou o tempo do Estado Nacional e chegada a hora de uma integração política supranacional (como a empreendida na Europa). Uma espécie, por assim dizer, de "novo republicanismo" com vocação mundial suscetível de conjurar a dupla escolha do novo desprendimento nacionalista e da dissolução do corpo político no mercado mundial.

Por fim, ainda em se tratando da temática de inclusão do outro, vale apena relembrar as reflexões anteriores de Habermas sobre essa temática em um de seus textos intitulado Erläuterungen zur Diskursethik (“Comentários à ética do discurso”), publicado em 1991. Nele já se encontram, embora ainda em estado de formação e vinculação com seu sistema filosófico, os fundamentos teóricos que foram posteriormente desenvolvidos e aqui expostos. Seu suprassumo pode ser percebido no seguinte extrato:

Tendo como ponto de referência uma comunidade comunicativa alargada de forma ideal, a
teoria moral abandona também todos os conceitos pré-sociais de pessoa. A individuação é
apenas o reverso da socialização. Só por meio de relações de reconhecimento recíproco é que
uma pessoa pode constituir e reproduzir sua identidade. Até o âmago mais interior da pessoa
está internamente ligado à periferia mais externa de uma rede extremamente ramificada de
relações comunicativas. A pessoa só se torna idêntica a si própria em proporção à sua exposição
comunicativa. As interações sociais que formam o Eu também o ameaçam-através das
dependências em que ele se implica e das contingências a que ele se expóe. A moral actua
como fonte de equilíbrio para esta susceptibilidade inerente ao próprio processo de
socialização. (HABERMAS, 1991, p. 96).

Aqui se torna claro que à sua ideia primaria da relação entre a "teoria moral", "individuação" e "exposição comunicativa", Habermas agregou um fundamento teórico mais profundo relacionando cada uma destas ideias com suas ideias anteriores desenvolvidas em 1992 no livro Faktizität und Geltung ("Direito e Democracia”, HABERMAS, 1997).

\section{A POLÍTICA DE INTERNAÇÃO COMPULSÓRIA}

No Brasil as drogas não foram, desde sempre, um problema do âmbito jurídico. Prova disso é que a primeira lei da qual se tem registros oficias a respeito da regulamentação do uso de drogas ou suas proibições data de 04 de outubro de 1830 que, ademais de regulamentar a venda de gêneros e 
remédios pelos boticários, tinha caráter proibitivo no que dizia respeito a comercialização e uso do pito de pango. Para os infratores da referida lei estavam previstas como punição uma multa (no caso de se tratar do vendedor) e três dias de cadeia (no caso dos usuários). ${ }^{2}$ Desde então a temática das drogas nunca mais esteve distante do âmbito jurídico.

Com o passar dos anos o esforço do Estado em combater às drogas denominadas "ilícitas" não parou de gerar sucessivas leis que tencionavam extinguir seu uso e comercialização. Assim sendo, em 1911 o Brasil assumiu em Haia o compromisso de fiscalização do uso de cocaína e ópio - cujo uso já era evidente em alguns extratos da sociedade. Com isso o Brasil se tornara parceiro de um processo que tomou proporções globais de combate às drogas.

Em seus desdobramentos as políticas de combate às drogas conheceram várias transformações e adequações culminando, atualmente, num disposto legal que tem gerado desconforto para algumas pessoas enquanto outras veem neste disposto um avanço considerável conhecido comumente como “internação compulsória".

Fato interessante é que esta postura em relação aos usuários tem sido compreendida por boa parte da população como algo novo, quando na realidade ela faz lembrar o Decreto ${ }^{\circ}$ 4.294, de 06 de julho de 19213 que, no seu artigo 6 $6^{\circ}$, regulamentava a internação compulsória de usuários de substâncias entorpecentes, ademais de criar um estabelecimento especial para atendimento de tais casos. $^{3}$

O que hoje denomina-se “internação compulsória” encontra seu respaldo jurídico na Lei Federal de Psiquiatria ( $N^{\circ}$ 10.216, de 2001). Ela consiste, como o próprio nome diz, na possibilidade disposta ao Estado, por meio de seu poder judiciário, de internar compulsoriamente indivíduos onde sejam compreendidos casos considerados extremos de transtorno mental e, por extensão de sentido, dependentes químicos.

Esta lei federal "possui dois grandes eixos: a questão da proteção e o redirecionamento do modelo assistencial" (BRITTO, 2004, p. 93). No caso específico da internação compulsória, dispensase a autorização familiar quando esta for determinada por juiz competente. Isto porque, o artigo $9^{\circ}$ da lei 10.216/01 dispõe o seguinte:

Art. $9^{\circ} \mathrm{A}$ internação compulsória é determinada, de acordo com a legislação vigente, pelo juiz competente, que levará em conta as condições de segurança do estabelecimento, quanto à salvaguarda do paciente, dos demais internados e funcionários.

\footnotetext{
${ }^{2}$ Cf.: MARTINS, Lourenço A. G. História internacional da droga. Disponível em: https://encod.org/2009-8/historiainternacional-da-droga/ Acesso em 06 dezembro 2013.

${ }^{3}$ BRASIL. Decreto lei n. 4.294, de 06 jul. 1921. Disponível em: https://www2.camara.leg.br/legin/fed/decret/19201929/decreto-4294-6-julho-1921-569300-norma-pl.html Acesso em 06 dezembro 2013.
} 
A mudança significativa em relação a internação compulsória é seu uso ostensivo e acentuado em relação aos usuários de drogas ilícitas. O governo criou, por assim dizer, medidas que viabilizaram de maneira mais ampla o cumprimento da lei10.216/01. E, com o objetivo de regulamentar a comunicação da internação psiquiátrica involuntária foi promulgada em 2002 a Portaria n $^{\circ}$ 2.391/GM que

Regulamenta o controle das internações psiquiátricas involuntárias (IPI) e voluntárias (IPV) de acordo com o disposto na Lei 10.216, de 6 de abril de 2001, e os procedimentos de notificação da Comunicação das IPI e IPV ao Ministério Público pelos estabelecimentos de saúde, integrantes ou não do SUS

Nela se faz notar que a internação compulsória não é a regra a partir de agora, mas a exceção prevista em lei. Pois a política prioritária continuará sendo a internação voluntária, por meio de convencimento do dependente químico de drogas ilícitas efetuado por agentes de saúde, assistentes sociais devidamente qualificados para tanto.

No caso em que se aplica a internação compulsória de crianças e adolescentes, o Estatuto da Criança e do Adolescente (ECriad) prevê, em seu artigo 230, que "privar a criança ou o adolescente de sua liberdade" constitui crime. Não obstante a isso o mesmo ECriad, em seu artigo 112, prevê a possibilidade de que colocar criança em abrigo como medida excepcional: "Os adolescentes portadores de doença ou deficiência mental receberão tratamento individual e especializado, em local adequado às suas condições”. Motivo pelo qual não há que se falar em contradição ou crime no tocante a lei de internação compulsória em seu cumprimento.

Por fim, cabe ainda mencionar que a internação compulsória, conforme prevista na legislação brasileira, está em consonância com Organização Mundial de Saúde (OMS), que reconhece a internação compulsória como opção de tratamento em seu documento intitulado "Principles of Drug Dependence Treatment", de 2008. Nele se lê que "[...] in exceptional crisis situations of high risk to self or others, compulsory treatment should be mandated for specific conditions and periods of time as specified by the law". ${ }^{4}$

\footnotetext{
4 ...] em situações excepcionais de alto risco, devido à crise, para si ou outras pessoas, o tratamento compulsório deve ser determinado sob condições e períodos de tempo específicos determinados por lei." (Tradução nossa). Cf.: UN Office on Drugs and Crime/World Health Organization, "Principles of Drug Treatment. Discussion Paper", United Nations Office on Drugs and Crime, 2008, p. 10. Disponível em: https://www.unodc.org/documents/drug-treatment/UNODC-WHOPrinciples-of-Drug-Dependence-Treatment-March08.pdf. Acesso em 06 dezembro 2013.
} 


\section{INTERNAÇÃO COMPULSÓRIA E TEORIA HABERMASIANA}

A internação compulsória, enquanto lei que visa erradicar problemas sócias de larga escala e com vastas consequências destrutivas causados pelo uso e, consequentemente, comercialização das drogas ilícitas no Brasil pode mesmo compreendida como um tipo de avanço jurídico quando examinada como um bloco em si sem relação com quaisquer outros fatores sociais. E eis seu problema fundamental: o modo como ela se relaciona com o todo social, econômico, político e cultural a seu redor.

Criada para impedir o avanço de maiores problemas sociais a política de internação compulsória negligência uma série de outros fatores como se eles simplesmente não existissem. Dentre tais fatores a teoria habermasiana nos faz perceber um de maneira especial: "a inclusão do outro".

Vimos acima como Habermas articula o problema da inclusão do outro não apenas de maneira simplista e em termos de uma inclusão sentimentalista do outro que é uma forma transvestida de paternalismo. E o paternalismo é também uma forma de exclusão social da qual a internação compulsória parece se aproximar bastante. Eis o motivo pelo qual em sua teoria de inclusão ele começa por demonstrar os substratos genealógico-cognitivos da moral. Vistos por ele como problemáticos e carentes de revisão.

A política de internação compulsória ainda pode ser confrontada com a teoria habermasiana no tocante ao fato de que ela ainda seja de cunho normativista. Ora, toda normatização pressupõe, ao menos em certa medida, um término ou uma pausa na atitude dialogal. Assim, alguém pode objetivar corretamente que a política de internação compulsória ainda se encontra em discussão, mas enquanto objetiva isso não se dá conta de que ela está em movimento e acontecendo enquanto se discute sobre ela.

A política de internação, como se pode observar em seus dispostos e nas suas regulações, também não leva em consideração os distintos âmbitos e problemas do mundo atual que não se resumem unicamente as drogas, mas dos quais a droga é, em parte se pode afirmar, uma consequência. Assim o que deveria ser um remédio atua também como droga: dá a falsa impressão de que os problemas são inexistentes quando na realidade eles se atenuam em nossa ausência de consciência.

Ademais disto, a reforma psiquiátrica tem contestado veementemente como, por exemplo, pelo Conselho Regional de Psicologia de São Paulo. ${ }^{5}$ As considerações ali expostas nos fazem lembrar da possibilidade de vivenciar negativamente o "passado como futuro" (HABERMAS, 1993) e parecem

\footnotetext{
${ }^{5}$ Disponível em: http://www.crpsp.org.br/PORTAL/comunicacao/artesgraficas/internacao_compulsoria/internacao_compulsoria_verso.pdf. Acessado em 06 dezembro 2013.
} 
atestar que nós ainda não nos precatamos de que vivenciamos atualmente aquilo que Habermas denominou como sendo "a era das transições" (HABERMAS, 2003).

Faz-se necessário, podemos afirmar, pôr em prática os mecanismos disponíveis para impedir que a identidade coletiva se torne um mecanismo de exclusão do diferente, pois somos alertados por Habermas que essa exclusão se dá por meio de uma vontade consciente de homogeneidade social e que provoca a marginalização interna de grupos sociais inteiros. Não é possível ser habermasiano e conivente com a política de internação compulsória que se assemelha a um saneamento social.

Contra a exclusão sistemática é preciso a defesa de que a política própria da democracia deve ser dirigida na direção da "inclusão do outro" (como visto anteriormente). Inclusão essa que seja capaz de promover a independência do indivíduo e o capacite a assumir suas responsabilidades, ao invés de “sumir” com ele dentro de uma espécie de depósito social.

\section{CONSIDERAÇÕES FINAIS}

De todo o disposto nesse trabalho ficou nítido que a muito que evoluir em relação a correta compreensão de como se combate as drogas sem excluir o usuário. Conforme se pode ver a política de internação compulsória se aproxima muito daquilo que era praticado em séculos passados e pode mesmo ser considerada uma regressão às práticas daquela época.

Afirmamos isto porque, se no Renascimento o mundo era povoado pelo Diabo e por seres imaginários tenebrosos, em nossa época ele é povoado pelo "diabo" das drogas e as compreensões imaginária que distam da realidade delas e de tudo que elas implicam. Nesse delírio e nessa fúria legisferante para erradicar as drogas, retrocedemos no tempo para nos vermos, conforme mencionado na introdução, prestes a construir uma nova "nau dos loucos":

[...] as cidades querendo se ver livres de seus loucos, embarcavam-nos, fazendo-os percorrer principalmente os rios do norte e leste europeus, e, em cada localidade que aportavam, eram reembarcados. Focault lê nesse gesto, que impige ao louco uma condição de prisioneiro da passagem - isto é, de passageiro eterno, sem destino e de origem ignorada -, uma metáfora do modo ambíguo e prenhe de significações como a loucura é percebida na Renascença. (PASSOS, et ali., 2009, p. 48).

Isto não significa que os loucos fossem corridos das cidades de modo sistemático. Existiram, durante toda a Idade Média e a Renascença, casas de detenção para os insanos, as quais não tinham qualquer objetivo de tratamento e só aceitavam os loucos da própria cidade. Eram principalmente os estrangeiros escorraçados. Foucault ressalta essa prática porque parece corresponder ou metaforizar certas significações sobre a loucura dominantes na época. Assim, predomina uma visão da loucura muito próxima da morte, do inumano, do sobrenatural. (PASSOS, et ali., p. 48). 
Nessa nova barcaça social da loucura, construída com o incentivo de nossos medos sociais assomados a negligência do Estado na promoção de políticas sócias que promovam o bem-estar e, consequentemente uma sociedade saudável, nossos doentes sociais que "merecem" ser internados compulsoriamente partem para um destino incerto. Posto que, simbolicamente, eles partem para o outro mundo - pois cada embarque é potencialmente o último -, e é desse outro mundo que nos chegará um "louco são" (recuperado pelo sistema?) desembarcando na cidade. 


\section{REFERÊNCIAS}

BRASIL. Estatuto da Criança e do Adolescente. Disponível em: http://www.planalto.gov.br/ccivil_03/leis/18069.htm. Acesso em: 05 dezembro 2013.

Decreto lei n. 4.294, de 06 jul. 1921. Disponível em: https://www2.camara.leg.br/legin/fed/decret/1920-1929/decreto-4294-6-julho-1921-569300-normapl.html. Acesso em 06 dezembro 2013. BRASIL. Lei n. 10.216, de 06 abr. 2001. Dispõe sobre a proteção e os direitos das pessoas portadoras de transtornos mentais e redireciona o modelo assistencial em saúde mental. Disponível em: Acesso em: 05 dezembro 2013.

Lei n. 10.216, de 06 abr. 2001. Dispõe sobre a proteção e os direitos das pessoas portadoras de transtornos mentais e redireciona o modelo assistencial em saúde mental. Disponível em: http://www.planalto.gov.br/ccivil_03/leis/leis_2001/110216.htm. Acesso em: 05 dezembro 2013.

Portaria n. ${ }^{\circ}$ 2391/GM, em 26 de dezembro de 2002. Regulamenta o controle das internações psiquiátricas involuntárias (IPI) e voluntárias (IPV) de acordo com o disposto na Lei 10.216, de 6 de abril de 2002, e os procedimentos de notificação da Comunicação das IPI e IPV ao Ministério Público pelos estabelecimentos de saúde, integrantes ou não do SUS. Disponível em: https://bvsms.saude.gov.br/bvs/saudelegis/gm/2017/MatrizesConsolidacao/comum/15791.html. Acesso em: 05 dezembro 2013.

BRITTO, Renata Corrêa. A internação psiquiátrica involuntária e a Lei 10.216/01: Reflexões acerca da garantia de proteção aos direitos da pessoa com transtorno mental. Rio de Janeiro: Escola Nacional de Saúde Pública, 2004 (Dissertação de mestrado).

FOCAULT. Michel. História da loucura na Idade Clássica. 8ª ed. São Paulo: Perspectiva, 2005.

HABERMAS, Jürgen. A inclusão do outro: Estudos de teoria política. São Paulo: Loyola, 2002. Comentários à ética do discurso. Lisboa: Instituto Piaget, 1991.

Consciência Moral e Agir Comunicativo. Rio de Janeiro: Tempo Brasileiro,

1989.

Tempo Brasileiro, 1997.

Direito e Democracia: Entre facticidade e validade. Volume I. Rio de Janeiro:

. Direito e Democracia: Entre facticidade e validade. Volume II. Rio de Janeiro: Tempo Brasileiro, 1997.

Era das transições. Rio de Janeiro: Tempo Brasileiro, 2003.

. Facticidad y validez: Sobre el derecho y el Estado democrático de derecho en términos de teoría del discurso. $4^{\mathrm{a}}$ ed. Madrid: Trotta, 2005.

Passado como futuro. Rio de Janeiro: Tempo Brasileiro, 1993.

Teoría de la Accíon Comunicativa, I: Racionalidad de la acción y racionalización social. Madrid: Taurus, 1999. 
Madrid: Taurus, 1992.

Teoría de la Accíon Comunicativa, II: Crítica de la razón funcionalista. Teoría y Praxis: Estudios de filosofía social. Madrid: Tacnos, 1987.

MARTINS, Lourenço A. G. A história internacional da droga. Disponível em: https://encod.org/2009-8/historia-internacional-da-droga/. Acesso em 06 dezembro 2013.

MATOS, Olgária C. F. A Escola de Frankfurt: luzes e sombras do iluminismo. São Paulo: Moderna, 1993.

MATTOS, Patrícia Castro. A Sociologia Política do Reconhecimento: as contribuições de Charles Taylor, Axel Honneth e Nancy Fraser. São Paulo: Annablume, 2006.

PASSOS; I. C. F.; BARBOZA, M. A. G. “Tempos e espaços da loucura: uma leitura foucaultiana”, in: PASSOS; I. C. F. Loucura e sociedade: discursos, práticas e significações sociais. Belo Horizonte: Argvmentvm, 2009, p. 43-57.

UREÑA, E. M. La teoría crítica de la sociedad de Habermas. Madrid: Tecnos, 1978. 